\title{
Oxidative stress in cystic fibrosis lung disease: an early event, but worth targeting?
}

\author{
Andreas Hector ${ }^{1}$, Matthias Griese ${ }^{2}$ and Dominik Hartl ${ }^{1}$
}

Affiliations: ${ }^{1} \mathrm{CF}$ Center, Dept of Pediatrics I, University of Tübingen, Tübingen, Germany. ${ }^{2} \mathrm{CF}$ Center, Hauner Children's Hospital, University of Munich, Member of the German Center for Lung Research (DZL), Munich, Germany.

Correspondence: Dominik Hartl, CF Center, Dept of Pediatrics I, University of Tübingen, Hoppe-Seyler-Strasse 1, Tübingen 72076, Germany. E-mail: dominik.hartlamed.uni-tuebingen.de

○

@ERSpublications

A recent study showed that oxidative stress occurs early in CF lung disease and represents a potential drug target http://ow.ly/vdH2P

Oxidative stress is a universal biological response, which plays a major role in a variety of inflammatory disease conditions, such as cardiovascular diseases or sepsis. In the lung, harmful oxidative stress mainly occurs in nonresolving pathologies, such as cystic fibrosis (CF) lung disease $[1,2]$ or, to a lesser extent, chronic obstructive pulmonary disease $[3,4]$. In CF, neutrophils are continuously recruited to the airways and liberate their toxic ingredients, particularly proteases and oxidants, in an uncontrolled fashion [5]. Anti-proteases and anti-oxidants shield the lung from free proteolytic and oxidative damage [6]. However, in CF the amount and duration of neutrophilic inflammation overwhelms these defence systems [2, 7]. The released proteases and reactive oxygen species, physiologically the neutrophil's major armamentarium to kill intracellular pathogens, as evidenced in patients with chronic granulomatous disease [8], degrade extracellular matrix components and immune receptors and oxidise proteins in the CF airway microenvironment in an uncontrolled manner.

Glutathione is the major antioxidant shield in the epithelial lining fluid of the human lung and protects this vulnerable area from oxidative stress. Previous reports supported the concept that the cystic fibrosis transmembrane conductance regulator (CFTR) itself transports glutathione, providing a potential explanation for the low glutathione levels in CF airways [9-11]. Alternatively to this CFTR-linked mechanism, activated neutrophils are also capable of oxidising and thereby disabling glutathione [12]. To date, the relative contribution of these two mechanisms and the time-point when glutathione loss occurs in CF lung disease in vivo remains poorly understood.

In this issue of the European Respiratory Journal, KeTtLE et al. [13] take a closer look at the relationship between glutathione and neutrophilic inflammation by studying bronchoalveolar lavage fluid from 167 infants with CF with a mean age of 3 years. KETTLE et al. [13] studied a whole panel of glutathione oxidation products and neutrophil-derived enzymes that can oxidise glutathione. This study provides evidence that: 1) loss of glutathione occurs early in CF lung disease; 2) oxidised glutathione closely correlates with neutrophil-derived products, mainly hypochlorous acid; and 3) pulmonary infection enhances oxidative stress and oxidative loss of glutathione.

The question arises of how specific are these findings for CF and what are the therapeutic consequences? We know that glutathione levels in airway lining fluids are low in a number of inflammatory conditions beyond $\mathrm{CF}$, including severe asthma [14]. In previous studies, glutathione levels were found to be decreased in

Received: Feb 252014 | Accepted: Feb 272014

Conflict of interest: None declared.

Copyright @ERS 2014 
patients with advanced CF lung disease [7], whereas in younger CF children only a tendency towards lower levels was found in infected CF patients [15]. When viewed in combination, this might explain the overlap in glutathione levels in the study by KETTLE et al. [13] between CF patients and the control group, consisting of children with persistent respiratory symptoms. Although it remains premature to conclude that neutrophil-derived products are solely responsible for the loss of glutathione in CF airways, the close correlation in this young CF population strongly supports the view that impaired CFTR-dependent glutathione transport is not primarily responsible for the loss of functional (non-oxidised) glutathione in $\mathrm{CF}$ airway fluids in vivo, but rather its consumption by inflammatory processes.

Therapeutically, augmenting epithelial lining fluid glutathione in CF patients by means of inhalation $[2,16]$ or oral administration of the glutathione prodrug $N$-acetylcysteine [17] is not a novel approach per se, but has not been clinically successful to date [18-20]. Several attempts to deliver glutathione into CF airways were capable of delivering substantial amounts of glutathione [18, 19, 21] and demonstrated reduced superoxide anion formation by inflammatory cells [21], as well as modulation of pulmonary immune responses [22]. However, parameters of oxidative stress (myeloperoxidase, ascorbic acid, uric acid and others) were not significantly affected in these studies $[18,19,22]$. Clinically, these previous studies further failed to show a substantial effect on lung function parameters, as demonstrated recently by a 6-month glutathione inhalation study in adult CF patients [19]. Having observed that, in line with the recent findings from the AREST (Australian Respiratory Early Surveillance Team) study, one may conclude that the events leading to glutathione loss occur very early in CF lung disease and, consequently, have to be targeted as soon as possible in the course of disease in order to prevent irreversible oxidative damage of lung tissue components. Since neutrophils release both oxidants and proteases, which act in a synergistic manner to cause harm to the pulmonary tissue [5], advanced therapeutic approaches may consider inhibiting oxidants and proteases simultaneously and very early in CF lung disease. Targeting proteases isn't a real "success story" in CF lung disease yet. On the one hand, anti-proteases delivered into the airways of CF patients dampened airway inflammation and decreased proteolytic activities [23-25]. However, on the other hand, these studies failed to demonstrate an effect on lung function, probably due to insufficient drug concentrations achieved at the pulmonary site of inflammation, the duration of the studies and/or the fact that those studies were performed in adult CF patients, where proteolytic lung damage may have gone too far to stop it. The recent study by the AREST consortium, in line with their previous study on elastase $[26,27]$, strongly encourage studies using anti-oxidants and/or protease inhibitors in CF infants instead of adults, even though these studies will require high doses of anti-proteases/anti-oxidants and some time in order to show effects on lung function parameters. As forced expiratory volume in $1 \mathrm{~s}$ is not a feasible readout for children $<5$ years of age, the multiple-breath washout/lung clearance index method might be used in these studies [28-30]. Glutathione is rapidly oxidised in contact with activated neutrophils, which is a highly relevant mechanism in CF airways, mainly through the action of myeloperoxidase-derived hypochlorous acid [12]. Based on this notion, direct inhibition of neutrophil-derived products that oxidise glutathione, such as hypochlorous acid or myeloperoxidase, could represent a more promising and efficient strategy. This is also discussed by KeTTLE et al. [13]. Patients with congenital myeloperoxidase deficiency have an absent or very mild clinical phenotype [31], suggesting that these approaches could be well tolerated in vivo.

The road is paved with more than one rationale to therapeutically target neutrophil products in early CF lung disease, in order to prevent their harmful and irreversible effect on lung tissue components. The clinical implementation of these concepts is hampered by costs, drug delivery issues and optimised readouts in this young age group, but the promises make it worth facing these challenges.

\section{References}

Galli F, Battistoni A, Gambari R, et al. Oxidative stress and antioxidant therapy in cystic fibrosis. Biochim Biophys Acta 2012; 1822: 690-713.

2 Cantin AM, White TB, Cross CE, et al. Antioxidants in cystic fibrosis. Conclusions from the CF antioxidant workshop, Bethesda, Maryland, November 11-12, 2003. Free Radic Biol Med 2007; 42: 15-31.

Kirkham PA, Barnes PJ. Oxidative stress in COPD. Chest 2013; 144: 266-273.

Rahman I, Adcock IM. Oxidative stress and redox regulation of lung inflammation in COPD. Eur Respir J 2006; 28: 219-242.

Hartl D, Gaggar A, Bruscia E, et al. Innate immunity in cystic fibrosis lung disease. J Cyst Fibros 2012; 11: 363-382. Rahman I, MacNee W. Oxidative stress and regulation of glutathione in lung inflammation. Eur Respir J 2000; 16: 534-554.

7 Roum JH, Buhl R, McElvaney NG, et al. Systemic deficiency of glutathione in cystic fibrosis. J Appl Physiol 1993; 75: 2419-2424.

8 Rieber N, Hector A, Kuijpers T, et al. Current concepts of hyperinflammation in chronic granulomatous disease. Clin Dev Immunol 2012; 2012: 252460.

9 Hudson VM. Rethinking cystic fibrosis pathology: the critical role of abnormal reduced glutathione (GSH) transport caused by CFTR mutation. Free Radic Biol Med 2001; 30: 1440-1461. 
10 Gao L, Kim KJ, Yankaskas JR, et al. Abnormal glutathione transport in cystic fibrosis airway epithelia. Am J Physiol 1999; 277: L113-L118.

11 Day BJ, van Heeckeren AM, Min E, et al. Role for cystic fibrosis transmembrane conductance regulator protein in a glutathione response to bronchopulmonary Pseudomonas infection. Infect Immun 2004; 72: 2045-2051.

12 Carr AC, Winterbourn CC. Oxidation of neutrophil glutathione and protein thiols by myeloperoxidase-derived hypochlorous acid. Biochem J 1997; 327: 275-281.

13 Kettle AJ, Turner, R, Gangell CL, et al. Oxidation contributes to low glutathione in the airways of children with cystic fibrosis. Eur Respir J 2014; 44: 122-129.

14 Fitzpatrick AM, Brown LA, Holguin F, et al. Levels of nitric oxide oxidation products are increased in the epithelial lining fluid of children with persistent asthma. J Allergy Clin Immunol 2009; 124: 990-996.

15 Hull J, Vervaart P, Grimwood K, et al. Pulmonary oxidative stress response in young children with cystic fibrosis. Thorax 1997; 52: 557-560.

16 Cantin AM. Potential for antioxidant therapy of cystic fibrosis. Curr Opin Pulm Med 2004; 10: 531-536.

17 Tirouvanziam R, Conrad CK, Bottiglieri T, et al. High-dose oral $\mathrm{N}$-acetylcysteine, a glutathione prodrug, modulates inflammation in cystic fibrosis. Proc Nat Acad Sci USA 2006; 103: 4628-4633.

18 Griese M, Ramakers J, Krasselt A, et al. Improvement of alveolar glutathione and lung function but not oxidative state in cystic fibrosis. Am J Respir Crit Care Med 2004; 169: 822-828.

19 Griese M, Kappler M, Eismann C, et al. Inhalation treatment with glutathione in patients with cystic fibrosis. A randomized clinical trial. Am J Respir Crit Care Med 2013; 188: 83-89.

20 Nash EF, Stephenson A, Ratjen F, et al. Nebulized and oral thiol derivatives for pulmonary disease in cystic fibrosis. Cochrane Databases Syst Rev 2009; 1: CD007168.

21 Roum JH, Borok Z, McElvaney NG, et al. Glutathione aerosol suppresses lung epithelial surface inflammatory cellderived oxidants in cystic fibrosis. J Appl Physiol 1999; 87: 438-443.

22 Hartl D, Starosta V, Maier K, et al. Inhaled glutathione decreases PGE2 and increases lymphocytes in cystic fibrosis lungs. Free Radic Biol Med 2005; 39: 463-472.

23 Griese M, Latzin P, Kappler M, et al. $\alpha_{1}$-Antitrypsin inhalation reduces airway inflammation in cystic fibrosis patients. Eur Respir J 2007; 29: 240-250.

24 Griese M, Kappler M, Gaggar A, et al. Inhibition of airway proteases in cystic fibrosis lung disease. Eur Respir J 2008; 32: 783-795.

25 McElvaney NG, Hubbard RC, Birrer P, et al. Aerosol $\alpha 1$-antitrypsin treatment for cystic fibrosis. Lancet 1991; 337: 392-394.

26 Sly PD, Gangell CL, Chen L, et al. Risk factors for bronchiectasis in children with cystic fibrosis. N Engl J Med 2013; 368: 1963-1970.

27 Davis SD, Ferkol T. Identifying the origins of cystic fibrosis lung disease. N Engl J Med 2013; 368: 2026-2028.

28 Stocks J, Thia LP, Sonnappa S. Evaluation and use of childhood lung function tests in cystic fibrosis. Curr Opin Pulm Med 2012; 18: 602-608.

29 Singer F, Stern G, Thamrin C, et al. A new double-tracer gas single-breath washout to assess early cystic fibrosis lung disease. Eur Respir J 2013; 41: 339-345.

30 Aurora $\mathrm{P}$, Stanojevic S, Wade A, et al. Lung clearance index at 4 years predicts subsequent lung function in children with cystic fibrosis. Am J Respir Crit Care Med 2011; 183: 752-758.

31 Nauseef WM. Myeloperoxidase deficiency. Hematol Oncol Clin North Am 1988; 2: 135-158. 